\title{
A Gibbs free energy minimization based model for liquid-liquid equilibrium calculation of a system containing oil, brine, and surfactant
}

\author{
Mostafa Hosseini $^{1}$ and Amir H. Mohammadi ${ }^{2}{ }^{*}$ \\ ${ }^{1}$ Department of Petroleum Engineering, Faculty of Chemical Engineering, Tarbiat Modares University, P.O. Box: 14115-4838, \\ Tehran, Iran \\ ${ }^{2}$ Discipline of Chemical Engineering, School of Engineering, University of KwaZulu-Natal, Howard College Campus, King George V \\ Avenue, Durban 4041, South Africa
}

Received: 23 December 2019 / Accepted: 13 February 2020

\begin{abstract}
Accurate and reliable phase equilibrium calculations of microemulsion systems are of great importance. This study deals with the thermodynamic modeling of Liquid-Liquid Equilibrium (LLE) of a system including oil ( $n$-decane), brine (containing $\mathrm{CaCl}_{2}$ salt), and ionic surfactant (sodium dodecyl sulfonate). Two models of UNIQUAC and UNIQUAC + Debye-Hückel were used for thermodynamic calculations. The LLE experimental data were utilized to estimate the binary interaction parameters of UNIQUAC model and the adjustable parameter, $b$, of the Debye-Hückel model. The thermodynamic model calculates the microemulsion phase's compositions by minimizing the Gibbs free energy of the LLE system using a combination of genetic algorithm and fmincon function in order to prevent local minima. The thermodynamic modeling results show an appropriate agreement with the experimental data. Accordingly, the presented model of this study can be used as a suitable method to investigate the liquid-liquid equilibrium of systems containing oil, water, and surfactant.
\end{abstract}

\section{Introduction}

Petroleum products (oil, gas, and fuels), colloidal systems, and those which result from biomass conversion are among the fluids that have received much attention in various industries $[1,2]$. Because of the high demand for oil around the world, more attention is being paid to Enhanced Oil Recovery (EOR) methods [3]. Given the pressure drop in conventional reservoirs, many methods are used to recover the residual oil in reservoirs [4]. For instance, water flooding has been extensively considered as an effective method in the secondary oil recovery [5]; however, given the high capillary forces and heterogeneity of reservoir, nearly $70 \%$ original oil in place remains in the reservoir [6]. Therefore, the importance of tertiary oil recovery methods is specified. In these methods, different chemicals including surfactants, polymers, and so on along with seawater are injected to oil reservoirs [7-9]. To this end, different surfactants, including cationic, anionic or even a mixture of these two, are widely used [10-13]. As a result of the surfactants injection, the surfactant is initially located due to its structure between the oil and water phases, which leads to the formation of a three-phase system including aqueous brine, oil as well

\footnotetext{
* Corresponding author: amir_h_mohammadi@yahoo.com
}

as, surfactant, and also reduces the interfacial tension [14-17]. Increasing the surfactants' concentration results in the formation of a continuous phase, or the microemulsion. Finally, a two-phase system consisting of oil and microemulsion phases, which are in equilibrium, are formed $[17,18]$.

According to the previous researches, one can conclude that surfactant plays a very important role in the LLE of oil, brine, and surfactant systems. Therefore, accurate and reliable phase equilibrium calculations of microemulsion systems to facilitate the EOR conditions are of great importance so that the exact number of phases and the values of the components are determined in equilibrium [19-22]. As indicated in the other researches, there are two methods for calculating liquid-liquid equilibrium: in the first method, the isoactivity equations are solved under mass balance constraints [23, 24], and in the second method, the Gibbs free energy minimization is addressed [25]. In the second method, the results are dependent on initial estimates, and poor estimates may lead to wrong solutions [26]. For instance, in 1999, Yushan and Zhihong proposed an algorithm for liquid-liquid phase equilibrium calculation. They utilized tangent plane distance function criterion for stability analysis so that this approach was considered as sufficient and necessary condition. Moreover, activity 
coefficient models, namely UNIQUAC and NRTL were used to formulate Gibbs free energy functions [27]. In 2018, Dadmohammadi et al. employed the NRTL, mNRTL1, and mNRTL2 activity coefficient models for the characterization of LLE systems [28]. Their study showed the efficiency of the modified NRTL models in characterization of LLE systems. Also in 2016, Li et al. unlike the use of minimizing the Gibbs free energy (coupled with stability test), solved isoactivity equations for their LLE calculations using NRTL model, and conducted their study on two-phase LLE systems. They concluded that this approach could be applied to multiphase systems [26]. It should be noted that both Equation of State (EOS) and activity coefficient models have been implemented in different researches for characterization of the phase behavior of LLE [29-35] and vapor-liquid equilibrium [36] systems. Riazi and Moshfeghian presented a thermodynamic approach using NRTL activity coefficient model. They used Debye-Hückel theory to calculate the long-range interactions. They investigated the LLE of a system containing water, oil, and surfactant. For the adjustable parameter of the NRTL model, the value of 0.1 was chosen. In addition, only two interaction parameters were optimized and others considered equal to zero [37].

In this study, the LLE of oil, brine, and surfactant systems was studied through Gibbs free energy minimization method on the data provided in Riazi and Moshfeghian's research [37]. To do so, two models of UNIQUAC and UNIQUAC + Debye-Hückel were used, and consequently the results were compared with the previous research.

\section{Experimental data}

As mentioned earlier, the experimental (phase equilibrium) data of a system including oil ( $n$-decane), brine (containing $\mathrm{CaCl}_{2}$ salt), and an ionic surfactant, named sodium dodecyl sulfonate, were obtained from Riazi and Moshfeghian's research [37]. The studied system includes two phases of oil and microemulsion, so that in each of the two phases, all three components of oil, brine, and surfactant are available. It should be noted that the salt presents in water is $\mathrm{CaCl}_{2}$ with a concentration of $500 \mathrm{mg} / \mathrm{L}\left(\mathrm{Ca}^{++}\right)$, which is equal to $0.138 \mathrm{wt} \%$. In addition, the experiments were carried out at a temperature of $20{ }^{\circ} \mathrm{C}$ and atmospheric pressure. Three concentrations of surfactants with values of $0.5 \mathrm{wt} \%, 1 \mathrm{wt} \%$, and $2 \mathrm{wt} \%$ were used in the experiments, and in each set of experiments ten different oil volumes ranging from $5 \%$ to $90 \%$ of the total volume of system were utilized. The initial mixture compositions for three sets of experiments as well as the physical properties and mole fractions of the components in microemulsion phase are presented in Tables 1-3, respectively. It is noteworthy that the $\phi$ parameter represents the molar ratio of the oil phase to the total number of mole in the system, the amount of which alters from 0 to 1 . It should be noted that numbers 1-3 are considered for oil, water, and surfactant molecules, respectively.

The structural parameters for the functional groups are reported in Table $4[38,39]$.
Table 1. The initial mixture compositions for three sets of experiments, $z_{j}^{\text {component }}[37]$.

\begin{tabular}{|c|c|c|c|}
\hline$J$ & $z_{j}(\mathrm{oil})$ & $z_{j}$ (water) & $z_{j}($ surfactant $)$ \\
\hline 1 & 0.0055 & 0.9943 & 0.0001 \\
\hline 2 & 0.0116 & 0.9883 & 0.0001 \\
\hline 3 & 0.0257 & 0.9741 & 0.0002 \\
\hline 4 & 0.0433 & 0.9565 & 0.0002 \\
\hline 5 & 0.0658 & 0.9340 & 0.0002 \\
\hline 6 & 0.0957 & 0.9041 & 0.0002 \\
\hline 7 & 0.1372 & 0.8626 & 0.0003 \\
\hline 8 & 0.1988 & 0.8009 & 0.0003 \\
\hline 9 & 0.2997 & 0.6999 & 0.0004 \\
\hline 10 & 0.4955 & 0.5039 & 0.0006 \\
\hline 11 & 0.0055 & 0.9942 & 0.0003 \\
\hline 12 & 0.0116 & 0.9881 & 0.0003 \\
\hline 13 & 0.0258 & 0.9738 & 0.0003 \\
\hline 14 & 0.0436 & 0.9561 & 0.0004 \\
\hline 15 & 0.0663 & 0.9333 & 0.0004 \\
\hline 16 & 0.0964 & 0.9031 & 0.0004 \\
\hline 17 & 0.1384 & 0.8610 & 0.0005 \\
\hline 18 & 0.2010 & 0.7984 & 0.0006 \\
\hline 19 & 0.3041 & 0.6951 & 0.0008 \\
\hline 20 & 0.5058 & 0.4930 & 0.0012 \\
\hline 21 & 0.0056 & 0.9938 & 0.0006 \\
\hline 22 & 0.0118 & 0.9876 & 0.0006 \\
\hline 23 & 0.0261 & 0.9732 & 0.0006 \\
\hline 24 & 0.0441 & 0.9552 & 0.0007 \\
\hline 25 & 0.0672 & 0.9320 & 0.0008 \\
\hline 26 & 0.0980 & 0.9011 & 0.0009 \\
\hline 27 & 0.1411 & 0.8579 & 0.0011 \\
\hline 28 & 0.2057 & 0.7931 & 0.0013 \\
\hline 29 & 0.3132 & 0.6851 & 0.0017 \\
\hline 30 & 0.5279 & 0.4696 & 0.0024 \\
\hline
\end{tabular}

\section{Thermodynamic model}

\subsection{The UNIQUAC activity coefficient model}

The molar excess Gibbs and activity coefficient functions of UNIQUAC model are as follows [40]:

$$
\begin{gathered}
\frac{g^{E}}{\mathrm{RT}}=\left(\frac{g^{E}}{\mathrm{RT}}\right)_{\text {combinatorial }}+\left(\frac{g^{E}}{\mathrm{RT}}\right)_{\text {residual }}, \\
\left(\frac{g^{E}}{\mathrm{RT}}\right)_{\text {combinatorial }}=\sum_{j=1}^{m} x_{i} \ln \frac{\Phi_{i}^{*}}{x_{i}}+\frac{z}{2} \sum_{i=1}^{m} x_{i} q_{i} \ln \frac{\theta_{i}}{\Phi_{i}^{*}}, \\
\left(\frac{g^{E}}{\mathrm{RT}}\right)_{\text {residual }}=-\sum_{i=1}^{m} x_{i} q_{i}^{\prime} \ln \left(\sum_{j=1}^{m} \theta_{j}^{\prime} \tau_{j i}\right),
\end{gathered}
$$


Table 2. The physical properties of the components [37].

\begin{tabular}{llcccccc}
\hline Comp. & \multicolumn{1}{c}{ Compound } & $\begin{array}{c}\text { Chemical or } \\
\text { linear formula }\end{array}$ & $\begin{array}{c}\mathrm{CAS} \\
\text { number }\end{array}$ & $M(\mathrm{~g} / \mathrm{mol})$ & $d_{20}\left(\mathrm{~g} / \mathrm{cm}^{3}\right)$ & $V_{20}\left(\mathrm{~cm}^{3} / \mathrm{mol}^{2}\right)$ & $\varepsilon$ \\
\hline 1 & Oil $(n$-dacane $)$ & $\mathrm{CH}_{3}\left(\mathrm{CH}_{2}\right)_{8} \mathrm{CH}_{3}$ & $124-18-5$ & 134 & 0.78 & 171.8 & 2.074 \\
2 & Water & $\mathrm{H}_{2} \mathrm{O}$ & $7732-18-5$ & 18.0 & 1.0 & 18.0 & 80.1 \\
3 & Surfactant & $\mathrm{CH}_{3}\left(\mathrm{CH}_{2}\right)_{11} \mathrm{SO}_{3} \mathrm{Na}$ & $2386-53-0$ & 272.38 & 1.0 & 272.38 & \\
& Calcium chloride & $\mathrm{CaCl}_{2}$ & $10043-52-4$ & 110.9 & & & \\
\hline
\end{tabular}

$V_{20}, d_{20}$, and $\varepsilon$ are the molar volume at $20^{\circ} \mathrm{C}$, liquid density at $20^{\circ} \mathrm{C}$, and the dielectric constant, respectively.

Table 3. The mole fractions (mole \%) of the components in microemulsion phase [37].

\begin{tabular}{|c|c|c|c|}
\hline Oil & Water & Surfactant & $100 \times \phi$ \\
\hline 0.18 & 99.81 & 0.014 & 0.37 \\
\hline 0.43 & 99.56 & 0.015 & 0.73 \\
\hline 0.15 & 99.83 & 0.016 & 2.42 \\
\hline 0.09 & 99.90 & 0.018 & 4.25 \\
\hline 0.36 & 99.62 & 0.021 & 6.24 \\
\hline 0.15 & 99.82 & 0.024 & 9.43 \\
\hline 0.33 & 99.64 & 0.030 & 13.43 \\
\hline 0.77 & 99.19 & 0.039 & 19.26 \\
\hline 1.05 & 98.89 & 0.057 & 29.23 \\
\hline 1.37 & 98.51 & 0.112 & 48.85 \\
\hline 0.22 & 99.75 & 0.029 & 0.33 \\
\hline 0.33 & 99.64 & 0.030 & 0.83 \\
\hline 0.48 & 99.49 & 0.033 & 2.12 \\
\hline 0.44 & 99.52 & 0.037 & 3.93 \\
\hline 0.51 & 99.45 & 0.042 & 6.15 \\
\hline 0.48 & 99.47 & 0.049 & 9.21 \\
\hline 0.64 & 99.30 & 0.060 & 13.29 \\
\hline 1.13 & 98.80 & 0.078 & 19.19 \\
\hline 1.51 & 98.37 & 0.115 & 29.34 \\
\hline 2.57 & 97.19 & 0.230 & 49.28 \\
\hline 0.18 & 99.76 & 0.058 & 0.38 \\
\hline 0.36 & 99.58 & 0.060 & 1.00 \\
\hline 0.54 & 99.40 & 0.066 & 2.44 \\
\hline 0.70 & 99.22 & 0.074 & 4.24 \\
\hline 0.88 & 99.03 & 0.084 & 6.57 \\
\hline 1.07 & 98.84 & 0.099 & 9.66 \\
\hline 1.38 & 98.50 & 0.121 & 13.98 \\
\hline 1.71 & 98.13 & 0.159 & 20.47 \\
\hline 3.15 & 96.61 & 0.236 & 31.27 \\
\hline 7.19 & 92.33 & 0.480 & 52.83 \\
\hline
\end{tabular}

$$
\begin{aligned}
\ln \gamma_{i}= & \ln \frac{\Phi_{i}^{*}}{x_{i}}+\frac{z}{2} q_{i} \ln \frac{\theta_{i}}{\Phi_{i}^{*}}+l_{i}-\frac{\Phi_{i}^{*}}{x_{i}} \sum_{j=1}^{m} x_{j} l_{j}-q_{i}^{\prime} \\
& \times \ln \left(\sum_{j=1}^{m} \theta_{j}^{\prime} \tau_{j i}\right)+q_{i}^{\prime}-q_{i}^{\prime} \sum_{j=1}^{n} \frac{\theta_{j}^{\prime} \tau_{i j}}{\sum_{k=1}^{n} \theta_{k}^{\prime} \tau_{k j}},
\end{aligned}
$$

Table 4. The structural parameters of the functional groups [38, 39].

\begin{tabular}{lccc}
\hline Functional group & $r$ & $q$ & $q \prime$ \\
\hline $\mathrm{Na}^{+}$ & 1.0612 & 1.0404 & 1.0404 \\
$\mathrm{SO}_{3}^{-}$ & 4.9130 & 2.8900 & 2.8900 \\
$\mathrm{H}_{2} \mathrm{O}$ & 0.9200 & 1.4000 & 1.0000 \\
$\mathrm{CH}_{2}$ & 0.6744 & 0.5400 & 0.5400 \\
$\mathrm{CH}_{3}$ & 0.9011 & 0.8480 & 0.8480 \\
\hline
\end{tabular}

Table 5. The constants of equation (12).

\begin{tabular}{lc}
\hline Constant & Value \\
\hline$e$ & $1.60218 \times 10^{-19} \mathrm{C}$ \\
$\varepsilon_{0}$ & $8.85419 \times 10^{-12} \mathrm{C}^{2} \mathrm{~N}^{-1} \mathrm{~m}^{-2}$ \\
$\varepsilon_{r}$ & 80.1 \\
$N_{\mathrm{A}}$ & $6.022 \times 10^{23}$ \\
$d_{s}$ & $998.2 \mathrm{~kg} \mathrm{~m}^{-3}$ \\
\hline
\end{tabular}

$$
\begin{gathered}
\theta_{i}=\frac{x_{i} q_{i}}{\sum_{j=1}^{m} x_{j} q_{j}} \quad \theta_{j}^{\prime}=\frac{x_{i} q_{i}^{\prime}}{\sum_{j=1}^{m} x_{j} q_{j}^{\prime}} \quad \Phi_{i}^{*}=\frac{x_{i} r_{i}}{\sum_{j=1}^{m} x_{j} r_{j}}, \\
\tau_{j i}=\exp \left(-\frac{a_{i j}}{T}\right), \\
r_{i}=\sum_{k} v_{k}^{(i)} R_{k}, \\
q_{i}=\sum_{k} v_{k}^{(i)} Q_{k}, \\
l_{j}=\frac{z}{2}\left(r_{j}-q_{j}\right)-\left(r_{j}-1\right),
\end{gathered}
$$

where $r, q$, and $q^{\prime}$ indicate molecular structure parameters of a pure component, expressing the volume and surface areas of molecule, respectively, where with the exception of water and some small alcohols, $q=q^{\prime}$. Also, the subscript $k$ and superscript $i$ in equations (7) and (8) refer to the group $k$ and the occurrence of the group $k$ in molecule $i$, respectively. The parameter $Z$, which implies the 
coordination number, is assumed as a fixed value of 10 . The variable $\Phi^{*}$ represents the segment fraction. In addition, $\theta$ and $\theta^{\prime}$ denote the area fractions of a simple and a hydrogen bonded molecule, respectively.

\subsection{Debye-Hückel theory}

The ionic activity coefficient for electrolyte is as follows [41]:

$$
\gamma_{ \pm}^{(m)}=\frac{-A_{\gamma}\left|Z_{+} Z_{-}\right| I^{1 / 2}}{1+I^{1 / 2}}+b I
$$

where $Z_{+}$and $Z_{-}$are the positive and negative charges of the electrolyte. The parameter $b$ is an adjustable parameter, and $I$ is the ionic strength which is defined as follows:

$$
I=\frac{1}{2} \sum_{i=\text { ion }} m_{i} Z_{i}^{2}
$$

where $m_{i}$ and $Z_{i}$ stand for the molality of ion $i(\mathrm{~mol} / \mathrm{kg}$ of water) and the valances of ions, respectively.

In Debye-Hückel theory, the $A_{\gamma}$ coefficient is calculated as follows:

$$
A_{\gamma}=\left(\frac{e^{2}}{\varepsilon_{0} \varepsilon_{r} \mathrm{RT}}\right)^{1.5} \frac{N_{\mathrm{A}}^{2}}{8 \pi}\left(2 d_{s}\right)^{0.5}
$$

In the calculations, it is assumed that the surfactant is fully dissociated into positive and negative ions just in the microemulsion phase, and the dissociation does not occur in the oil phase. The experimental data of this study were measured at $20{ }^{\circ} \mathrm{C}$ [37]. The constant values utilized in equation (12) are presented in Table 5. The calculated value for $A_{\gamma}$ is equal to 1.1667 .

\subsection{Gibbs free energy minimization}

Calculations were performed based on the Gibbs free energy minimization [19]. Total Gibbs free energy of a mixture of $n_{c}$ components and $n_{p}$ phases is obtained from the following equations:

$$
G=\sum_{k=1}^{n_{p}} n^{k} g^{k}=\sum_{k=1}^{n_{p}}\left(\sum_{i=1}^{n_{c}} n_{i}^{k}\right) g^{k},
$$

where,

$$
\begin{aligned}
& \sum_{k=1}^{n_{p}} n_{i}^{k}=z_{i} F \quad i=1,2, \ldots, n_{c}, \\
& 0 \leq n_{i}^{k} \leq z_{i} F \quad i=1,2, \ldots, n_{c},
\end{aligned}
$$

where $n^{k}, n_{i}^{k}, F$, and $z_{i}$ are the total number of moles in phase $k$, the number of moles of component $i$ phase $k$, the total number of moles in input feed, and the molar fraction of component $i$ in the input feed, respectively. In the case of using the Gibbs energy functions for the LLE calculations, the following equation is utilized to calculate the Gibbs energy of the mixture:

$$
G=\sum_{k=1}^{n_{p}} \sum_{i=1}^{n_{c}} n_{i}^{L(k)}\left[\ln \left(x_{i}^{L(k)} \gamma_{i}^{L(k)}\right)\right]
$$

where the superscript, $L(k)$ denotes to liquid phase $k$, and $\gamma_{i}$ represents the activity coefficient. Through the minimization of the above equation, equilibrium concentrations are calculated in each phase. In the above equation, the mole number of each component in each phase is unknown that can be calculated by minimizing. To achieve this goal, change of variables, $\beta_{i}^{k}$ (for $i=1$, $\left.2, \ldots, n_{c} ; k=1,2, \ldots, n_{p}-1\right)$, is used which is as follows:

$$
\begin{gathered}
n_{i}^{1}=\beta_{i}^{1} z_{i} F \quad i=1,2, \ldots, n_{c} \\
n_{i}^{k}=\beta_{i}^{k}\left(z_{i} F-\sum_{j=1}^{k-1} n_{i}^{j}\right) \quad i=1,2, \ldots, n_{c} \quad k=2, \ldots, n_{p}-1, \\
n_{i}^{n_{p}}=z_{i} F-\sum_{j=1}^{n_{p}-1} n_{i}^{j} \quad i=1,2, \ldots, n_{c}
\end{gathered}
$$

The unknown variables are $\beta_{i}^{k}$, which are calculated by minimizing. The following limitation must be applied to avoid negative or imaginary answers:

$$
10^{-15} \leq \beta_{i}^{k} \leq 1 \quad i=1,2, \ldots, n_{c} .
$$

\subsection{Liquid-liquid equilibrium calculation}

In this study, to find the accurate values of $\beta_{i}^{k}$ in the minimization of Gibbs energy and the binary interaction parameters of UNIQUAC and UNIQUAC + Debye-Hückel models, a combination of genetic algorithm and fmincon function (fmincon function within MATLAB environment) was utilized which leads to calculation of logical answers in all points.

One of the methods to solve constrained and unconstrained optimization problems is to use genetic algorithm based on natural selection, a process that leads to biological evolution. The way it works is that the genetic algorithm frequently modifies a population of individual solutions. At each stage, the genetic algorithm randomly chooses individuals from the current population as parents and also it utilizes them to produce children for the next generation. Consequently, throughout consecutive generations, the population "evolves" toward an optimal solution. Genetic algorithms can be applied to solve different optimization problems that cannot be implemented using standard optimization algorithms. These include problems where the objective function is stochastic, discontinuous, nonlinear, or non-differentiable [42, 43]. In addition, the fmincon function is used to find a constrained minimum of a scalar function whose variables start from an initial estimation.

As we know, in the calculations of the liquid-liquid equilibrium, the equilibrium condition is as follows:

$$
x_{i}^{\mathrm{O}} \gamma_{i}^{\mathrm{O}}-x_{i}^{\mathrm{ME}} \gamma_{i}^{\mathrm{ME}}=0,
$$


where $\mathrm{O}$ and $\mathrm{ME}$ denote to the oil and microemulsion phases, respectively. In equation (21), the activity coefficients are calculated based on the mole fraction. The problem with this is that the Debye-Hückel model is based on molality. Therefore, the conversion of the unit of activity coefficient from molality to mole fraction is required. To do so, the equation provided by Panah et al. can be used [44], which is as follows:

$$
x_{i} \gamma_{i}^{(x)}=\frac{m_{i} \gamma_{i}^{(m)}}{\frac{1000}{18.01528}+\sum_{j \neq \text { water }} m_{j}},
$$

where $x, \gamma^{(x)}, m, \gamma^{(m)}$ are the mole fraction, mole fraction based activity coefficient, molality, and molality based activity coefficient, respectively. In the above equation, the term of " $1000 / 18.01528$ " is the mole number of water contained in $1 \mathrm{~kg}$.

When using the UNIQUAC + Debye-Hückel model for the surfactant, the UNIQUAC model is used to calculate the activity in the oil phase and the Debye-Hückel model is applied for the microemulsion phase. Therefore, the normalization of the Debye-Hückel model is necessary and it is proposed as follows:

$$
\ln \gamma_{3}=\ln \gamma_{3}^{*}+\ln \gamma_{3}^{\infty},
$$

where $\gamma_{3}^{*}$ and $\gamma_{3}^{\infty}$ are the calculated activity coefficient of the surfactant by the Debye-Hückel model and the surfactant activity coefficient at infinite dilution, respectively. In the calculations, the value of $\gamma_{3}^{\infty}$ was obtained by fitting which is reported in Table 8.

To find the binary interaction parameters of UNIQUAC activity coefficient model, the adjustable parameter of Debye-Hückel model $(b)$, as well as the surfactant activity coefficient at infinite dilution $\left(\gamma_{3}^{\infty}\right)$, equation (21) should be solved. Afterwards the Gibbs free energy minimization will be performed.

In UNIQUAC + Debye-Hückel model, the activity coefficient of $n$-decane and water in both phases are calculated using UNIQUAC equations. The activity coefficient of the surfactant in the oil phase is also calculated using UNIQUAC equations, but the activity coefficient in the microemulsion phase is calculated using Debye-Hückel equations.

In the last step of the present study, Absolute Average Deviation (AAD) is used to find the quality of the predicted data compared to the experimental data. The AAD\% is defined as below:

$$
\operatorname{AAD} \%=\frac{100}{N} \sum_{i=1}^{N}\left|\frac{X^{\exp }(i)-X^{\text {cal }}(i)}{X^{\exp }(i)}\right|
$$

where $N$ is the number of tie lines and $X$ is the variable whose error is calculated. In addition, the superscripts "exp" and "cal" refer to experimental and calculated data, respectively.

\section{Results and discussion}

The structural parameters for oil, water, and surfactant molecules in UNIQUAC activity coefficient model are
Table 6. The structural parameters for oil, water, and surfactant molecules in UNIQUAC activity coefficient model.

\begin{tabular}{lrrr}
\hline Substance & \multicolumn{1}{c}{$r$} & \multicolumn{1}{c}{$q^{\prime}$} \\
\hline Oil & 7.1974 & 6.0160 & 6.0160 \\
Water & 0.9200 & 1.4000 & 1.0000 \\
Surfactant & 14.2937 & 10.7184 & 10.7184 \\
\hline
\end{tabular}

Table 7. The regressed binary parameter for UNIQUAC model using binary LLE data.

\begin{tabular}{lccccc}
\hline$\tau_{12}$ & $\tau_{21}$ & $\tau_{13}$ & $\tau_{31}$ & $\tau_{23}$ & $\tau_{32}$ \\
\hline 0.0058 & 1.3078 & 0.3415 & 0.0902 & 0.3474 & 1.1618 \\
\hline
\end{tabular}

calculated using equations (7) and (8). These parameters are presented in Table 6 .

As Teh and Rangaiah mentioned in their study, in order to have precise phase equilibrium calculations, an accurate global minimum is required [19]. As we know, although the genetic algorithm optimizes the parameters globally, this optimization is not accurate, since different initial guesses for parameters give different answers. Moreover, functions such as fmincon optimize the parameters locally. To solve these problems, in the present study, the combination of these two algorithms was used so that both binary interaction and $\beta_{i}^{R}$ parameters are first optimized by genetic algorithm and then by fmincon function, this procedure leads to accurate results.

The binary interaction parameters for UNIQUAC and UNIQUAC + Debye-Hückel models are presented in Tables 7 and 8, respectively.

The UNIQUAC and UNIQUAC + Debye-Hückel models have 6 and 7 binary interaction parameters, respectively. In UNIQUAC + Debye-Hückel model, full dissociation of the surfactant into two positive and negative ions in the microemulsion phase is assumed, but in UNIQUAC model, no dissociation is considered.

The calculated values of the compositions (\%) in the microemulsion phase as well as $\phi$ values (\%) for UNIQUAC and UNIQUAC + Debye-Hückel models are presented in Table 9. In addition, for a better comparison, for example the predicted values of the present study for surfactant composition as well as $\phi$ values are shown in Figures 1 and 2 , respectively, as compared to the experimental data and the model presented by Riazi and Moshfeghian [37].

It should be mentioned that the mixture of water and $\mathrm{CaCl}_{2}$ is not considered as a pseudo component. The concentration of salt in the initial mixture is very low and its presence is ignored in the oil phase.

The AAD\% of the present modeling results are presented in Table 10 in comparison with the results acquired by Riazi and Moshfeghian [37].

Due to the low concentrations of surfactants, the addition of electrolyte term or, in other words, the consideration of long-range interactions, has little effect on 
Table 8. The regressed binary parameter for UNIQUAC + Debye-Hückel model using binary LLE data.

\begin{tabular}{lccccccc}
\hline$\tau_{12}$ & $\tau_{21}$ & $\tau_{13}$ & $\tau_{31}$ & $\tau_{23}$ & $\tau_{32}$ & $b$ & $\gamma_{3}^{\infty}$ \\
\hline 0.0006 & 1.3172 & 0.7695 & 0.1881 & 0.1089 & 0.7111 & 1.6117 & 1.0313 \\
\hline
\end{tabular}

Table 9. Calculated molar composition (\%) of microemulsion phase using UNIQUAC and UNIQUAC + Debye-Hückel models.

\begin{tabular}{|c|c|c|c|c|c|c|c|}
\hline \multicolumn{4}{|c|}{ UNIQUAC } & \multicolumn{4}{|c|}{ UNIQUAC + Debye-Hückel } \\
\hline Oil & Water & Surfactant & $100 \times \phi$ & Oil & Water & Surfactant & $100 \times \phi$ \\
\hline 0.21 & 99.77 & 0.01 & 0.34 & 0.22 & 99.77 & 0.01 & 0.33 \\
\hline 0.21 & 99.77 & 0.01 & 0.96 & 0.22 & 99.77 & 0.01 & 0.95 \\
\hline 0.21 & 99.76 & 0.02 & 2.40 & 0.22 & 99.76 & 0.02 & 2.36 \\
\hline 0.21 & 99.76 & 0.02 & 4.21 & 0.22 & 99.76 & 0.02 & 4.13 \\
\hline 0.21 & 99.76 & 0.02 & 6.51 & 0.22 & 99.76 & 0.02 & 6.39 \\
\hline 0.21 & 99.75 & 0.02 & 9.58 & 0.22 & 99.76 & 0.02 & 9.39 \\
\hline 0.22 & 99.74 & 0.03 & 13.83 & 0.22 & 99.74 & 0.03 & 13.56 \\
\hline 0.22 & 99.74 & 0.03 & 20.14 & 0.22 & 99.74 & 0.04 & 19.75 \\
\hline 0.22 & 99.71 & 0.05 & 30.48 & 0.22 & 99.72 & 0.06 & 29.88 \\
\hline 0.23 & 99.65 & 0.11 & 50.55 & 0.23 & 99.65 & 0.12 & 49.55 \\
\hline 0.22 & 99.74 & 0.03 & 0.33 & 0.22 & 99.75 & 0.03 & 0.33 \\
\hline 0.22 & 99.74 & 0.03 & 0.96 & 0.22 & 99.75 & 0.03 & 0.94 \\
\hline 0.22 & 99.74 & 0.03 & 2.41 & 0.22 & 99.75 & 0.03 & 2.37 \\
\hline 0.22 & 99.73 & 0.04 & 4.23 & 0.22 & 99.74 & 0.04 & 4.16 \\
\hline 0.22 & 99.73 & 0.04 & 6.56 & 0.22 & 99.74 & 0.04 & 6.44 \\
\hline 0.22 & 99.73 & 0.04 & 9.64 & 0.22 & 99.73 & 0.04 & 9.46 \\
\hline 0.22 & 99.71 & 0.05 & 13.95 & 0.22 & 99.72 & 0.06 & 13.68 \\
\hline 0.23 & 99.69 & 0.07 & 20.36 & 0.22 & 99.70 & 0.07 & 19.97 \\
\hline 0.23 & 99.64 & 0.11 & 30.93 & 0.23 & 99.65 & 0.11 & 30.32 \\
\hline 0.26 & 99.49 & 0.23 & 51.59 & 0.26 & 99.50 & 0.24 & 50.57 \\
\hline 0.22 & 99.71 & 0.06 & 0.34 & 0.22 & 99.72 & 0.06 & 0.34 \\
\hline 0.22 & 99.71 & 0.06 & 0.97 & 0.22 & 99.72 & 0.06 & 0.96 \\
\hline 0.22 & 99.71 & 0.06 & 2.44 & 0.22 & 99.72 & 0.06 & 2.40 \\
\hline 0.23 & 99.69 & 0.07 & 4.28 & 0.22 & 99.70 & 0.07 & 4.21 \\
\hline 0.23 & 99.68 & 0.08 & 6.64 & 0.23 & 99.69 & 0.09 & 6.52 \\
\hline 0.23 & 99.66 & 0.09 & 9.80 & 0.23 & 99.67 & 0.10 & 9.62 \\
\hline 0.24 & 99.63 & 0.12 & 14.21 & 0.23 & 99.64 & 0.13 & 13.94 \\
\hline 0.25 & 99.58 & 0.16 & 20.83 & 0.24 & 99.60 & 0.16 & 20.43 \\
\hline 0.27 & 99.48 & 0.24 & 31.84 & 0.26 & 99.49 & 0.25 & 31.21 \\
\hline 0.33 & 99.15 & 0.51 & 53.81 & 0.36 & 99.16 & 0.48 & 52.81 \\
\hline
\end{tabular}

the improvement of results. Previously, this conclusion was reported by Riazi and Moshfeghian [37]. Moreover, the comparison between the results obtained by Riazi and Moshfeghian [37] with the results of this study shows a much better performance of the UNIQUAC and UNIQUAC + Debye-Hückel models, especially in predicting the oil composition in the microemulsion phase.

It is necessary to mention that all three models have poor performances in predicting the molar fraction of the oil component. However, UNIQUAC and UNIQUAC + Debye-Hückel models predict the molar fraction of the oil component with a higher accuracy than the NRTL model used by Riazi and Moshfeghian [37]. Nevertheless, in the analysis of the obtained results, this point should be considered that the NRTL model requires four fitting parameters to describe the proposed LLE system; while the obtained lower errors by the UNIQUAC and UNIQUAC + DebyeHückel models were originated from more fitting values 


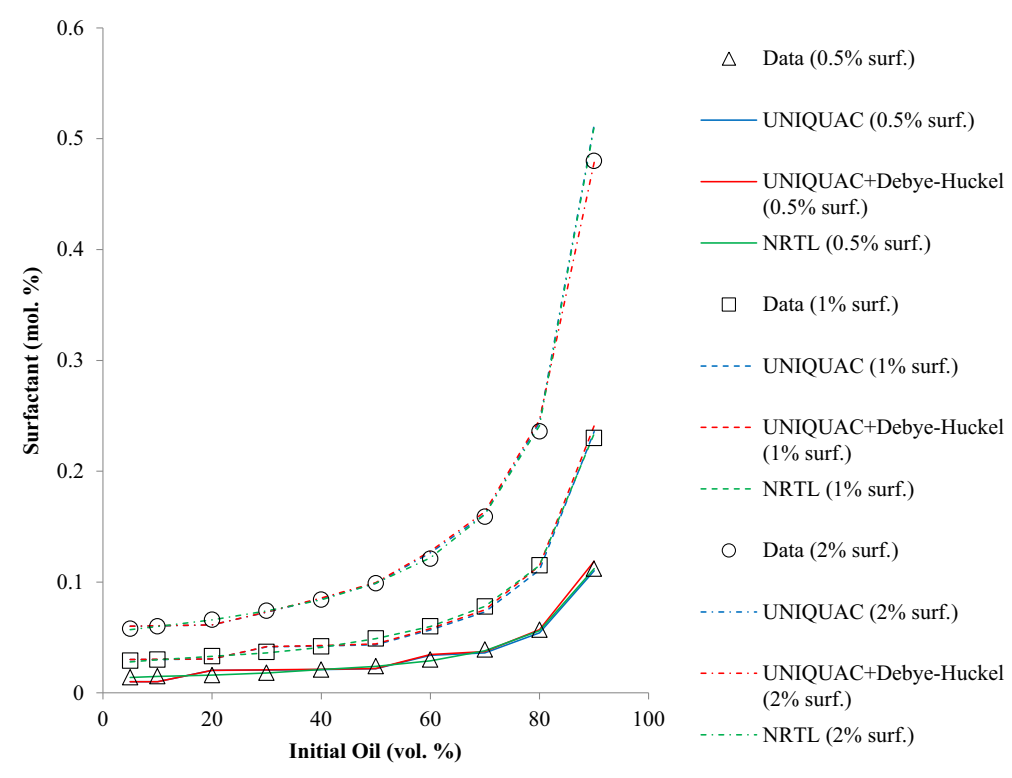

Fig. 1. Prediction of surfactant composition in the microemulsion phase using UNIQUAC and UNIQUAC + Debye-Hückel in comparison with the experimental data and the presented NRTL model by Riazi and Moshfeghian [37] for oil/brine/surfactant system.

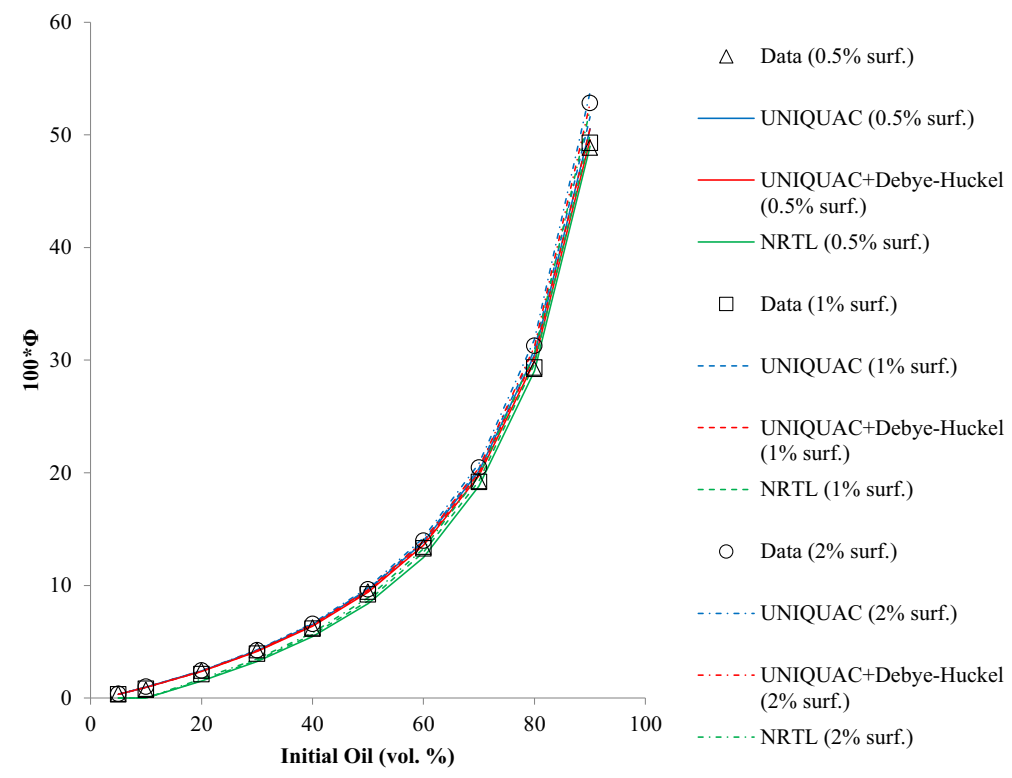

Fig. 2. Prediction of $\Phi$ values using UNIQUAC and UNIQUAC + Debye-Hückel in comparison with the experimental data and the presented NRTL model by Riazi and Moshfeghian [37] for oil/brine/surfactant system.

Table 10. The AAD\% values.

\begin{tabular}{lcccr}
\hline Model & AAD $\%\left(x_{1}\right)$ & AAD $\%\left(x_{2}\right)$ & AAD $\%\left(x_{3}\right)$ & AAD $(\Phi)$ \\
\hline UNIQUAC & 62.2 & 0.8 & 7.5 & 5.3 \\
UNIQUAC + Debye-Hückel & 62.6 & 0.8 & 7.2 & 4.2 \\
NRTL [37] & 154.5 & 0.8 & 1.0 & 27.9 \\
\hline
\end{tabular}


and it is logical to present better performances than the NRTL model. Regarding the molar fraction of the water component, all three models give the same results. The NRTL model employed by Riazi and Moshfeghian [37] offers a more successful performance in predicting the molar fraction of the surfactant component, and there is an appropriate agreement with the experimental values. The UNIQUAC and UNIQUAC + Debye-Hückel models represent an excellent performance in predicting $\Phi$. However, in the NRTL model used by Riazi and Moshfeghian [37], a very high error is observed.

One of the goals pursued in modeling studies could be to reduce the fitting parameters to the lowest possible number as the high number of fitting parameters can reduce the validity of the model. In 2015, Dadfar and Biria studied the LLE of the system with the same experimental data used in the present study [21]. They used 35 fitting parameters. However, the error obtained by them were not considerably better.

It should be mentioned that, as the oil composition is not reported in the literature [37], the oil is considered as $n$-decane. Moreover, in modeling study carried out on the same system, it is common to consider oil as $n$-decane [21].

\section{Conclusion}

Gibbs free energy minimization based modeling of the LLE conditions for a system containing oil, brine, and surfactant was investigated in this work. This modeling approach employs UNIQUAC and UNIQUAC + Debye-Hückel activity coefficients models. A combination of genetic algorithm and fmincon function was used which leads to calculation of reasonably accurate results. According to Table 10, one can note that the investigated model in this study displays an acceptable overall performance in predicting the molar fractions of components as compared to a previous study reported in literature so that the experimental and computational values were slightly different. It is concluded that the addition of electrolyte term has little effect on the improvement of results given the low concentrations of surfactants. In fact, considering the electrolyte term, the $\mathrm{AAD} \%$ value for the mole fractions of the components and $\phi$ changes less than $1 \%$. The model can be used as a robust method to investigate the liquid-liquid equilibrium of systems containing oil, water, and surfactant.

\section{References}

1 Mahi M.R., Ouaar F., Negadi A., Bahadur I., Negadi L. (2018) Excess/deviation properties of binary mixtures of 2,5-dimethylfuran with furfuryl alcohol, methyl isobutyl ketone, 1-butanol and 2-butanol at temperature range of (293.15-323.15) K, Oil Gas Sci. Technol. - Rev. IFP Energies nouvelles $\mathbf{7 3}, 64$.

2 Jafari A., Hasani M., Hosseini M., Gharibshahi R. (2019) Application of CFD technique to simulate enhanced oil recovery processes: Current status and future opportunities, Pet. Sci. 1-23. https://doi.org/10.1007/s12182-019-00363-7
3 Hirasaki G.J., Miller C.A., Puerto M. (2008) Recent advances in surfactant EOR, in: IPTC 2008: International Petroleum Technology Conference, 3-5 December, Kuala Lumpur, Malaysia.

4 Chen X., Feng Q., Liu W., Sepehrnoori K. (2017) Modeling preformed particle gel surfactant combined flooding for enhanced oil recovery after polymer flooding, Fuel 194, 42-49.

5 Craig F.F. (1971) The reservoir engineering aspects of waterflooding, Vol. 3, HL Doherty Memorial Fund of AIME, New York.

6 Kumar N., Mandal A. (2018) Surfactant stabilized oil-inwater nanoemulsion: Stability, interfacial tension, and rheology study for enhanced oil recovery application, Energy Fuels 32, 6452-6466.

7 Shi S., Wang Y., Wang L., Jin Y., Wang T., Wang J. (2015) Potential of spontaneous emulsification flooding for enhancing oil recovery in high-temperature and high-salinity oil reservoir, J. Dispers. Sci. Technol. 36, 660-669.

8 Liu S., Zhang D., Yan W., Puerto M., Hirasaki G.J., Miller C.A. (2008) Favorable attributes of alkaline-surfactantpolymer flooding, SPE J. 13, 5-16.

9 Manrique E.J., Thomas C.P., Ravikiran R., Izadi Kamouei M., Lantz M., Romero J.L., Alvarado V. (2010) EOR: current status and opportunities, in:SPE Improved Oil Recovery Symposium, 24-28 April, Tulsa, OK. Society of Petroleum Engineers.

10 Puerto M.C. (2001) Surfactants: Fundamentals and Applications in the Petroleum Industry-Cambridge University Press, 2000, pp. 621,@ \$85.00 (US \$140.00)(hardback), ISBN 0-521-64067-9, Chem. Eng. J. 83, 1, 63.

11 Li Y., Zhang W., Kong B., Puerto M., Bao X., Sha O., Shen Z., Yang Y., Liu Y., Gu S. (2016) Mixtures of anionic/cationic surfactants: A new approach for enhanced oil recovery in low-salinity, high-temperature sandstone reservoir, SPE J. 21, 1-164.

12 Ahmadi S., Hosseini M., Tangestani E., Mousavi S.E., Niazi M. (2020) Wettability alteration and oil recovery by spontaneous imbibition of smart water and surfactants into carbonates, Pet. Sci. 1-10. https://doi.org/10.1007/s12182019-00412-1.

13 Dehaghani A.H.S., Badizad M.H. (2019) Impact of ionic composition on modulating wetting preference of calcite surface: Implication for chemically tuned water flooding, Colloids Surf. A Physicochem. Eng. Asp. 568, 470-480.

14 Sheng J.J. (2010) Modern chemical enhanced oil recovery: theory and practice, Gulf Professional Publishing, Oxford, UK.

15 Flaaten A., Nguyen Q.P., Pope G.A., Zhang J. (2008) A systematic laboratory approach to low-cost, high-performance chemical flooding, in: SPE Symposium on Improved Oil Recovery, 20-23 April, Tulsa, OK. Society of Petroleum Engineers.

16 Hirasaki G., Zhang D.L. (2004) Surface chemistry of oil recovery from fractured, oil-wet, carbonate formations, $S P E$ J. 9, 151-162.

17 Rosen M.J. (2004) Emulsification by surfactants, in: Surfactants Interfacial Phenomena, 3rd edn., Wiley, Hoboken, NJ, pp. 303-331.

18 Winsor P.A. (1948) Hydrotropy, solubilisation and related emulsification processes, Trans. Faraday Soc. 44, 376-398.

19 Teh Y.S., Rangaiah G.P. (2002) A study of equation-solving and Gibbs free energy minimization methods for phase equilibrium calculations, Chem. Eng. Res. Des. 80, 745-759. 
20 Ashrafizadeh S.N., Motaee E., Hoshyargar V. (2012) Emulsification of heavy crude oil in water by natural surfactants, J. Pet. Sci. Eng. 86, 137-143.

21 Dadfar B., Biria D. (2015) Application of group contribution-NRTL model with closure to predict LLE behavior of an oil/brine/surfactant system, J. Chem. Eng. Data 60, 2575-2584.

22 Jin L., Budhathoki M., Jamili A., Li Z., Luo H., Ben Shiau B.J., Delshad M., Harwell J.H. (2017) Predicting microemulsion phase behavior using physics based HLD-NAC equation of state for surfactant flooding, J. Pet. Sci. Eng. 151, 213-223.

23 Privat R., Jaubert J.-N., Privat Y. (2013) A simple and unified algorithm to solve fluid phase equilibria using either the gamma-phi or the phi-phi approach for binary and ternary mixtures, Comput. Chem. Eng. 50, 139-151.

24 Panah H.S. (2018) Modeling binary vapor-liquid equilibrium data containing perfluorocarbons using the Peng-Robinson and the PC-SAFT equations of state, Int. J. Refrig. 85, 13-26.

25 Li Z., Mumford K.A., Shang Y., Smith K.H., Chen J., Wang Y., Stevens G.W. (2014) Analysis of the nonrandom two-liquid model for prediction of liquid-liquid equilibria, $J$. Chem. Eng. Data 59, 2485-2489.

26 Li Z., Mumford K.A., Smith K.H., Chen J., Wang Y., Stevens G.W. (2016) Solution structure of isoactivity equations for liquid-liquid equilibrium calculations using the nonrandom two-liquid model, Ind. Eng. Chem. Res. 55, 2852-2859.

27 Yushan Z.H.U., Zhihong X.U. (1999) A reliable method for liquid-liquid phase equilibrium calculation and global stability analysis, Chem. Eng. Commun. 176, 133-160.

28 Dadmohammadi Y., Gebreyohannes S., Neely B.J., Gasem K.A.M. (2018) Application of modified NRTL models for binary LLE phase characterization, Ind. Eng. Chem. Res. 57, 7282-7290.

29 Boshkov L.Z., Yelash L.V. (1997) Closed-loops of liquidliquid immiscibility in binary mixtures predicted from the Redlich-Kwong equation of state, Fluid Phase Equilib. 141, 105-112.

30 Sofyan Y., Ghajar A.J., Gasem K.A.M. (2003) A systematic method to predict cloud point temperature and solid precipitation, Pet. Sci. Technol. 21, 409-424.

31 Domańska U., Morawski P., Wierzbicki R. (2006) Phase diagrams of binary systems containing n-alkanes, or cyclohexane, or 1-alkanols and 2, 3-pentanedione at atmospheric and high pressure, Fluid Phase Equilib. 242, 154-163.

32 Giovanoglou A., Adjiman C.S., Jackson G., Galindo A. (2009) Fluid phase stability and equilibrium calculations in binary mixtures: Part II: Application to single-point calculations and the construction of phase diagrams, Fluid Phase Equilib. 275, 95-104.

33 Królikowska M., Karpińska M. (2013) Phase equilibria study of the (N-octylisoquinolinium thiocyanate ionic liquid + aliphatic and aromatic hydrocarbon, or thiophene) binary systems, J. Chem. Thermodyn. 63, 128-134.

34 Królikowska M., Karpińska M., Zawadzki M. (2013) Phase equilibria study of (ionic liquid + water) binary mixtures, Fluid Phase Equilib. 354, 66-74.

35 Reynel-Ávila H.E., Bonilla-Petriciolet A., Tapia-Picazo J.C. (2019) An artificial neural network-based NRTL model for simulating liquid-liquid equilibria of systems present in biofuels production, Fluid Phase Equilib. 483, 153-164.

36 Nasrifar K., Rahmanian N. (2018) Equations of state with group contribution binary interaction parameters for calculation of two-phase envelopes for synthetic and real natural gas mixtures with heavy fractions, Oil Gas Sci. Technol. - Rev. IFP Energies nouvelles 73, 7.

37 Riazi M.R., Moshfeghian M. (2009) A thermodynamic model for LLE behavior of oil/brine/ionic-surfactant/alcohol co-surfactant systems for EOR processes, J. Pet. Sci. Eng. 67, $75-83$.

38 Cheng H., Kontogeorgis G.M., Stenby E.H. (2005) Correlation and prediction of environmental properties of alcohol ethoxylate surfactants using the UNIFAC method, Ind. Eng. Chem. Res. 44, 7255-7261.

39 Qiu T., Li S., Li S., Wu Y. (2009) Liquid-liquid phase equilibria of the ternary system of water/1, 4-dioxane/ dihydromyrcene, Fluid Phase Equilib. 280, 84-87.

40 Prausnitz J.M., Lichtenthaler R.N., De Azevedo E.G. (1998) Molecular thermodynamics of fluid-phase equilibria, Pearson Education, London, UK.

41 Kontogeorgis G.M., Folas G.K. (2009) Thermodynamic models for industrial applications: From classical and advanced mixing rules to association theories, John Wiley \& Sons, Hoboken, NJ.

42 Sivanandam S.N., Deepa S.N. (2008) Genetic algorithms, in: Introduction to genetic algorithms, Springer, Berlin, Germany, pp. 15-37.

43 Gen M., Cheng R., Lin L. (2008) Network models and optimization: Multiobjective genetic algorithm approach, Springer Science \& Business Media, Berlin, Germany.

44 Panah H.S., Mohammadi A.H., Ramjugernath D. (2016) Development of a novel approach for modeling acid gas solubility in alkanolamine aqueous solution, J. Nat. Gas Sci. Eng. 34, 112-123. 